\title{
Job Adjustment Strategy for Predictive Maintenance in Semi-Fully Flexible Systems Based on Machine Health Status
}

\author{
Thirupathi Samala ${ }^{1}$, Vijaya Kumar Manupati ${ }^{1}$, Bethalam Brahma Sai Nikhilesh ${ }^{1}$, \\ Maria Leonilde Rocha Varela ${ }^{2, *(1)}$ and Goran Putnik ${ }^{2}$ \\ 1 Department of Mechanical Engineering, NIT Warangal, Warangal 506004, India; \\ thirupathisamalaa@gmail.com (T.S.); manupati.vijay@nitw.ac.in (V.K.M.); \\ nikhileshsai17@gmail.com (B.B.S.N.) \\ 2 Department of Production and Systems, School of Engineering, University of Minho, \\ 4804-533 Guimarães, Portugal; putnikgd@dps.uminho.pt \\ * Correspondence: leonilde@dps.uminho.pt; Tel.: +351-253-510-765
}

Citation: Samala, T.; Manupati, V.K.; Nikhilesh, B.B.S.; Varela, M.L.R.; Putnik, G. Job Adjustment Strategy for Predictive Maintenance in Semi-Fully Flexible Systems Based on Machine Health Status. Sustainability 2021, 13, 5295. https://doi.org/ $10.3390 /$ su13095295

Academic Editor: Sunkuk Kim

Received: 5 April 2021

Accepted: 6 May 2021

Published: 10 May 2021

Publisher's Note: MDPI stays neutral with regard to jurisdictional claims in published maps and institutional affiliations.

Copyright: (c) 2021 by the authors. Licensee MDPI, Basel, Switzerland. This article is an open access article distributed under the terms and conditions of the Creative Commons Attribution (CC BY) license (https:/ / creativecommons.org/licenses/by/ $4.0 /)$.

\begin{abstract}
Complex systems consist of multiple machines that are designed with a certain extent of redundancy to control any unanticipated events. The productivity of complex systems is highly affected by unexpected simultaneous machine failures due to overrunning of machines, improper maintenance, and natural characteristics. We proposed realistic configurations with multiple machines having several flexibilities to handle the above issues. The objectives of the proposed model are to reduce simultaneous machine failures by slowing down the pace of degradation of machines, to improve the average occurrence of the first failure time of machines, and to decrease the loss of production. An approach has been developed using each machine's degradation information to predict the machine's residual life based on which the job adjustment strategy where machines with a lower health status will be given a high number of jobs to perform is proposed. This approach is validated by applying it in a fabric weaving industry as a real-world case study under different scenarios and the performance is compared with two other key benchmark strategies.
\end{abstract}

Keywords: semi-fully flexible systems; degradation modelling; residual life prediction; job adjustment strategy

\section{Introduction}

Production industries are adapted to face a certain level of challenges, although many firms are incapable of meeting the accelerated pace of change to keep up with the current global competition and technological advancements. Digital transformation driven by smart manufacturing is the basis of the current paradigm shift. Most factories are composed of resources such as machines, assembly lines, and automatic devices that are properly integrated but not always connected. In order to make a factory smarter, the Industrial Internet of Things (IIOT) has emerged as a new and innovative platform that enables Industry 4.0 key technologies [1-3]. In handling customized orders that are low in volume, frequent demand shifts, and long lead times, current manufacturing systems' configurations are not capable enough to manage the production process. Moreover, every machine in the production system has its own health status and, therefore, its remaining useful life (RUL). Its degradation status is highly responsible for the operational performance of the production system [4].

In this unique circumstance, profound research activity is necessary for the development of smart factories in the industrial world. Although the maximum rate of production of a particular machine is designed to be greater than its actual need, according to the reports from the Federal Reserve Board, the United States' fabrication industries are facing nearly 20 percent of redundancy, which is an alarming issue for the production system 
industries [5,6]. However, this is not uncommon because an enormous number of machines tend to degrade at a similar rate, particularly when an equal amount of workload is allocated to those machines [7]. Therefore, evaluation of system performance in real-time by capturing the performance of a machine is a challenge.

Although, a good amount of research investigated the effect of component-level and machine-level degradation on system performance, a significant research gap exists on the unit-level analysis for controlling the degradation of machines in order to enhance the system-level performance. The proper choice of machine configuration greatly impacts the production system with regard to its machine reliability and system reliability. As a result, numerous scholars have published articles by optimizing the configurations to get better productivity [8-11].

Therefore, this study seeks to address the following questions:

1. How can a mathematical model be developed to minimize the average degradation level of all machines with a job adjustment strategy in the industries by considering the machine failure condition?

2. How can the proposed model be applied to the fabric weaving industry to test the efficiency in real-world situations?

Hence, in this paper, we proposed different configurations having different degrees of flexibility to estimate the system performance under simultaneous multiple-machine breakdown in a real-time environment. Here, we developed a stochastic linear degradation model to find the real-time degradation coefficient of each machine in a system at every instance. We established a case study with the key assumption that includes the degradation rate of each machine as a random variable following a normal distribution to apprehend the deviation in the degradation process due to natural characteristics. Hence, a Bayesian approach was deployed to update the prior distribution of the degradation coefficient to get a posterior distribution with the help of measurements that were collected in real-time and then the remaining useful life of machines was predicted from degradation signals. With the available health status value of each machine and their corresponding degrees of flexibility, the dynamic job adjustment strategy was applied to achieve the maximum output for the system. The job adjustment strategy is the assignment greater jobs to machines having poorer health status and vice versa. The greater work will lead to the machine's failure as early as possible, by that time the failed machine's pending jobs can be assigned to the remaining functional machines. In this way, the production rate is maintained and the overlap of machine failures can be reduced. In the context of this paper, predictive maintenance means predicting the health status of individual machines and, based on this health status, maintenance is done by improving the average occurrence of the first failure of the machines by predicting how much workload needs to be assigned to the machine for the next step. To the best of the authors' knowledge, there have been very few works on degradation rate prediction to estimate the real-time system-level performance. Through the proposed method, we contributed to the literature by developing a model that can predict the real-time health status of a machine and can help in protecting the production system from the overlap of machine failures to enable a smart factory.

On the whole, the contributions in this paper are summarized as follows:

- Proposed realistic configurations that are flexible and able to withstand changes in demand and the occurrence of breakdowns.

- Developed an objective function that slows the average degradation rate of machines by assigning a number of jobs to each machine based on the health status of that machine at each time interval.

- Validated proposed models in real-world situations.

The remainder of the paper is as follows: Section 2 provides a comprehensive overview of the relevant literature. Section 3 demonstrates the degradation modelling based on the flexibility of a manufacturing system framework. Section 4 discusses the development of a job adjustment methodology. Next, Section 5 describes the experimentation procedure. 
Section 6 discusses the analysis part of the dynamic job adjustment strategy. Finally, Section 7 presents conclusions and a discussion of future research.

\section{Literature Review}

Many studies have been conducted in the industrial production systems field although most of these studies have focused on component-level or machine-level degradation models to estimate the system performance. The degradation model defines a particular time-to-failure distribution [12]. Most of the researchers investigated component-level degradation, where the Bayesian updating method has been implemented to update the prior distribution based on real-time condition monitoring information and majorly focused on demonstrating the progression of the degradation process in every step to predict RUL.

In this literature, few studies are related to the design of a sustainable manufacturing system $[13,14]$. The integration of a degradation model for those systems has been mentioned by Gebraeel et al. [15], who implemented a Bayesian method for updating parameters and to predict the RUL of a bearing component. Hao et al. [16] and Song et al. [17] adopted the stochastic model and proposed a prognostic method to predict the residual life of each component in a composite manufacturing system by modelling degradation signals as an instantaneous stochastic process. The functional form of degradation endeavours to explain probabilistically the progression of the physical degradation process. Various techniques have been explained by Bian et al. [18], and they have modelled the evolution of degradation signals based on sensor data to estimate lifetime distribution. Later, Deutsch et al. [19] conducted research focused on prediction of the RUL of a rotating element with big data by presenting a deep-learning-based technique. Their technique has been tested and validated by collecting the data from a gear test rig. Similar work has been carried out by Ren et al. [20], a deep-learning-based method has been proposed to predict the RUL of a bearing component combined with the deep neural network and deep auto encoder. Further, supervised and unsupervised data analysis techniques have been used $[19,21,22]$ for the maintenance of a vessel based on its condition in a diesel-electric gas propulsion plant.

At the machine level, a case study has been presented for finding the degradation level by monitoring industrial pumps [23]. In this work, vibration data were collected from a chemical plant on 30 industrial pumps for a period of 2.5 years, and by applying the random forest algorithm, Key Condition Indices (KCIs) were found for condition-based monitoring. Similarly, data analysis and simulation tools have been used to analyse the machine failure data and system failure prediction, and a novel procedural approach has been proposed by [24]. Later, to reduce the impact of the degradation process on machine performance and machining precision, using sensory data such as emission rate, maintenance rate, and production rate, the performance indices have been identified by $[25,26]$.

$\mathrm{Ni}$ et al. [27] mentioned that system degradation is not a single-staged process instead it is a multi-stage process in real life. Li et al. [28] proposed a method for predicting the RUL by changing the degradation rate of systems and causing conditional signal jumps to change points as the two factors. With this information, a multi-stage stochastic degradation model was proposed by [29], using Bayesian updating methods to extract real-time data from machines and update the degradation model for finding the RUL for degraded machines. Further, numerous studies focused on the modelling of the degradation process with an insight to capture the degradation [28-32]. Few more papers studied various techniques for predicting the RUL and understanding the progression of degradation in machines [22,33-37].

To the best of the author's knowledge, only a few studies, e.g., Chandra et al. [7], Hao et al. [16], and Manupati et al. [38], address the phenomena of controlling the pace of degradation among the machines in a real-time manufacturing environment. Their studies proposed a workload strategy to dynamically control the degradation rate by predicting the residual life on parallel and hybrid configurations. Past studies mostly concentrate on parallel and hybrid configurations. Through this, we contribute to the literature on the problems of developing smart factories by proposing a method that can predict the 
real-time health status of the machines and minimize the average degradation level of all machines in a semi, fully flexible configuration environment by assigning the number of jobs to be processed on them dynamically. Further, it can help in protecting the system from the overlap of machine failure to create a smart factory.

\section{Problem Description}

We developed a linear degradation model for the proposed configurations associated with their manufacturing flexibility ranging from single-degree to fully flexible systems to control the pace of degradation among the machines for preventing the system from failure and indirectly controlling the loss of production of the system. To highlight the main idea, these systems undergo various analyses to predict the RUL of the machines that further improves the throughput through the minimization of the average degradation level. We define "throughput rate" as the overall output of the system, i.e., $\mathrm{TH}(\mathrm{x})=$ $\sum_{q=1, r=1}^{N(x)} O_{(q, r)}(x)$, where $\mathrm{TH}(x)$ represents the throughput rate at the time $x$, and $N(x)$ presents the number of machines. Here, we assume that the machines in the system are identical in nature. Now, let the number of operating machines at time $x$, be $\widetilde{N}(x)$, then the maximum throughput rate becomes $\sum_{q=1, r=1}^{\widetilde{N}(x)} C_{(q, r)}$, where $C_{(q, r)}$ indicates the "capacity" of a machine $q, r$ at time $x$. The throughput rate of a system concerning demand is defined as $T H(x)=\min \left[\sum_{q=1, r=1}^{\widetilde{N}(x)} C_{(q, r)}, D\right]$, where $D$ stands for "Demand". If demand of the system is less than capacity, $\sum_{q=1, r=1}^{\widetilde{N}(x)} C_{(q, r)} \geq D$, then the throughput rate can be considered as equal to the demand, $T H(x)=D$. Alternatively, when the capacity of the operating machines is lower than the demand, $\sum_{q=1, r=1}^{\widetilde{N}(x)} C_{(q, r)} \leq D$, then the throughput rate becomes equal to the maximum capacity of the operating machines, $T H(x)=\sum_{q=1, r=1}^{\widetilde{N}(x)} C_{(q, r)}$, which in turn raises the possibility of assigning the maximum amount of jobs to the machines. Here, $0 \leq O_{(q, r)}(x) \leq C_{(q, r)}$, for $q, r \in 1,2, \ldots, N, O_{(q, r)}(x)$ denotes assigned jobs for the machine $q, r$ at time $x$ and acts as a control variable. When machine breakdown occurs, the job processed on the machine becomes zero for the machine $q, r$ at the time $x$, i.e., $O_{(q, r)}(x)=0$.

\subsection{System Model Description}

Yoram et al. [39] pointed out the impact of various configurations on manufacturing system performance in terms of productivity, reliability, and life cycle cost. Among all the existing manufacturing systems' configurations, we considered flexible real-time configurations, i.e., one-degree, two-degree, semi-flexible, and fully flexible configurations. Flexible systems consist of $N$ identical machines operating simultaneously to process the assigned number of jobs. Here, when a job arrives, it has to be assigned to any available machines in the following configuration to be completed.

To recap, the main highlight of this paper is to determine the number of jobs that are to be assigned to each machine based on the health status of a machine at a unit time. Each of the models illustrated in Figure $1 \mathrm{a}-\mathrm{d}$ have a different level of flexibility. In this paper, we deliberated the degree of flexibility as the ability of a machine to adjust the assigned number of jobs for completion in response to failure or maintenance. For instance, Figure 1a presents a one-degree flexible environment, here machines work individually and simultaneously in a linear path to fulfil the necessity of the system, but if the machine $(1,1)$ fails, the pending assigned jobs on the machine $(1,1)$ can be processed by the adjacent machine $(1,2)$ depending upon the availability of the machine, stating one-degree flexibility. Figure $1 \mathrm{~b}$ articulates a two-degree flexible environment, here the availability of machines for job adjustment increases, i.e., in case of failure in the machine $(1,1)$, the adjacent machine $(1,2)$ or machine $(2,2)$ can process the pending jobs of the machine $(1,1)$. Followed by this are semi-flexible and fully flexible configurations in Figure $1 c, d$, respectively, where the 
options for workload adjustment are more in comparison to one-degree and two-degree flexible systems.

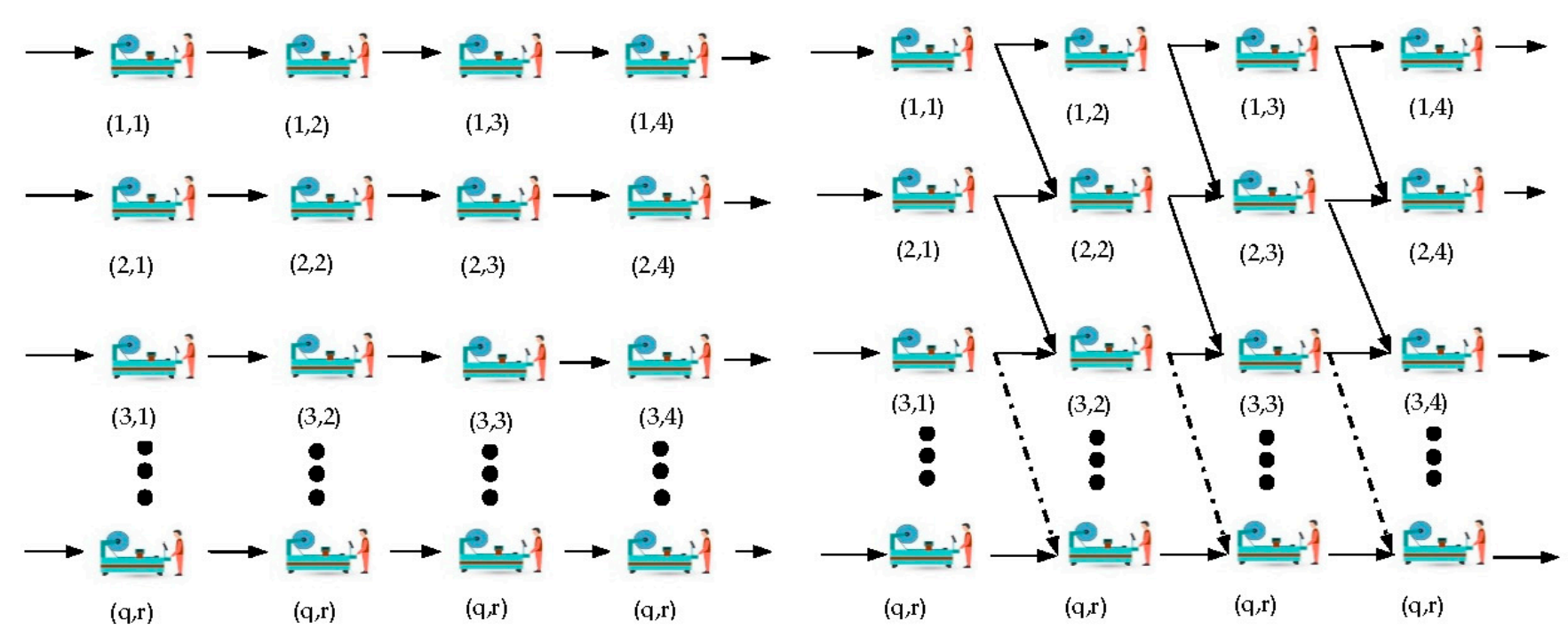

(a) For flexibility equal to 1 (One-degree flexible system) (b) For flexibility equal to 2 (two-degree flexible system)

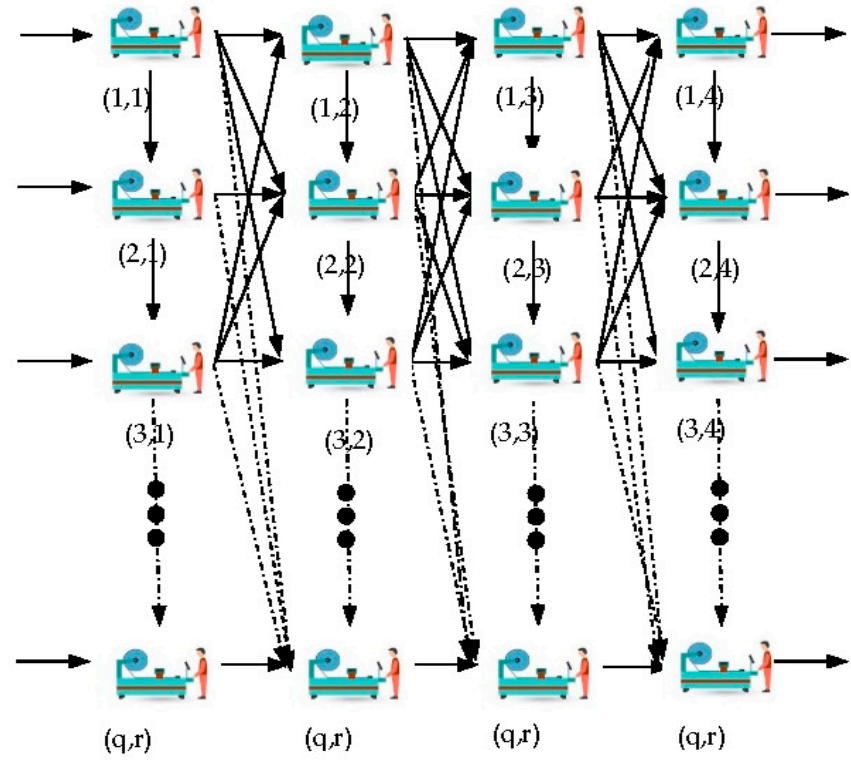

(c) For semi-flexible system configuration

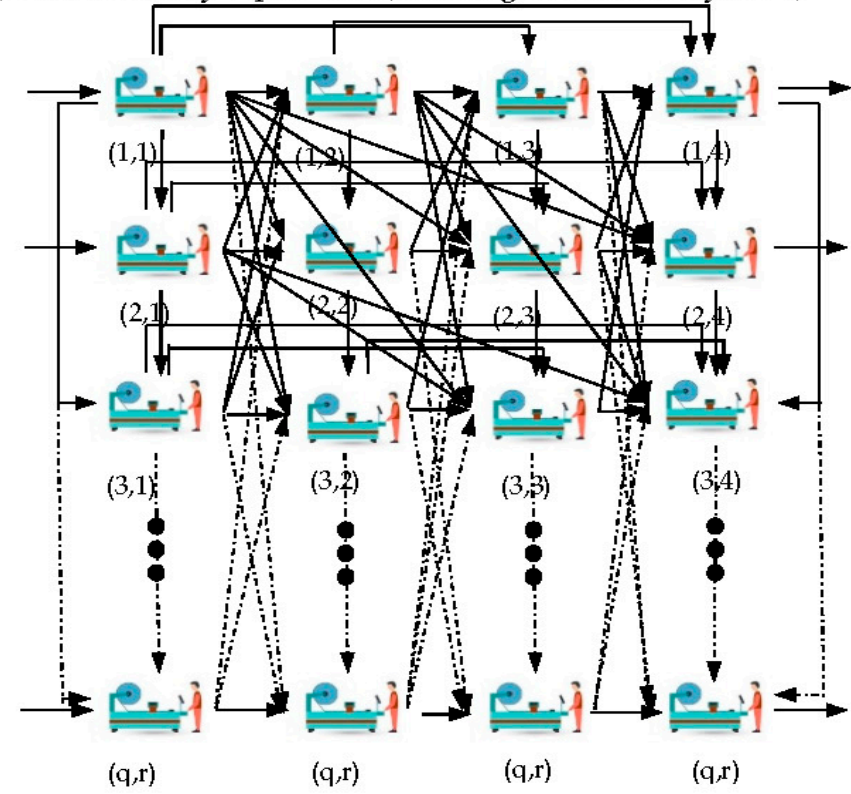

(d) For a fully flexible system configuration

Figure 1. Proposed flexible configurations.

\subsection{Essential Assumptions}

Demand is constant in the system, whereas the resulting number of jobs can vary on machines at a certain time.

1. The degradation coefficient for the machine $q, r$, i.e., $\alpha_{(q, r)}$ is unknown and random. For that, we assumed "machine to machine variability" to capture the uncertainty in the manufacturing environment.

2. At a time, only one job can be handled on one machine.

3. Once a machine initiates the processing of a job, the obstruction of its processing is not allowed. 
4. Machine failure is only considered in relation to its degradation rate.

\subsection{Proposed Degradation Framework}

At first, we propose a framework of the methodology followed in this paper as depicted in Figure 2.

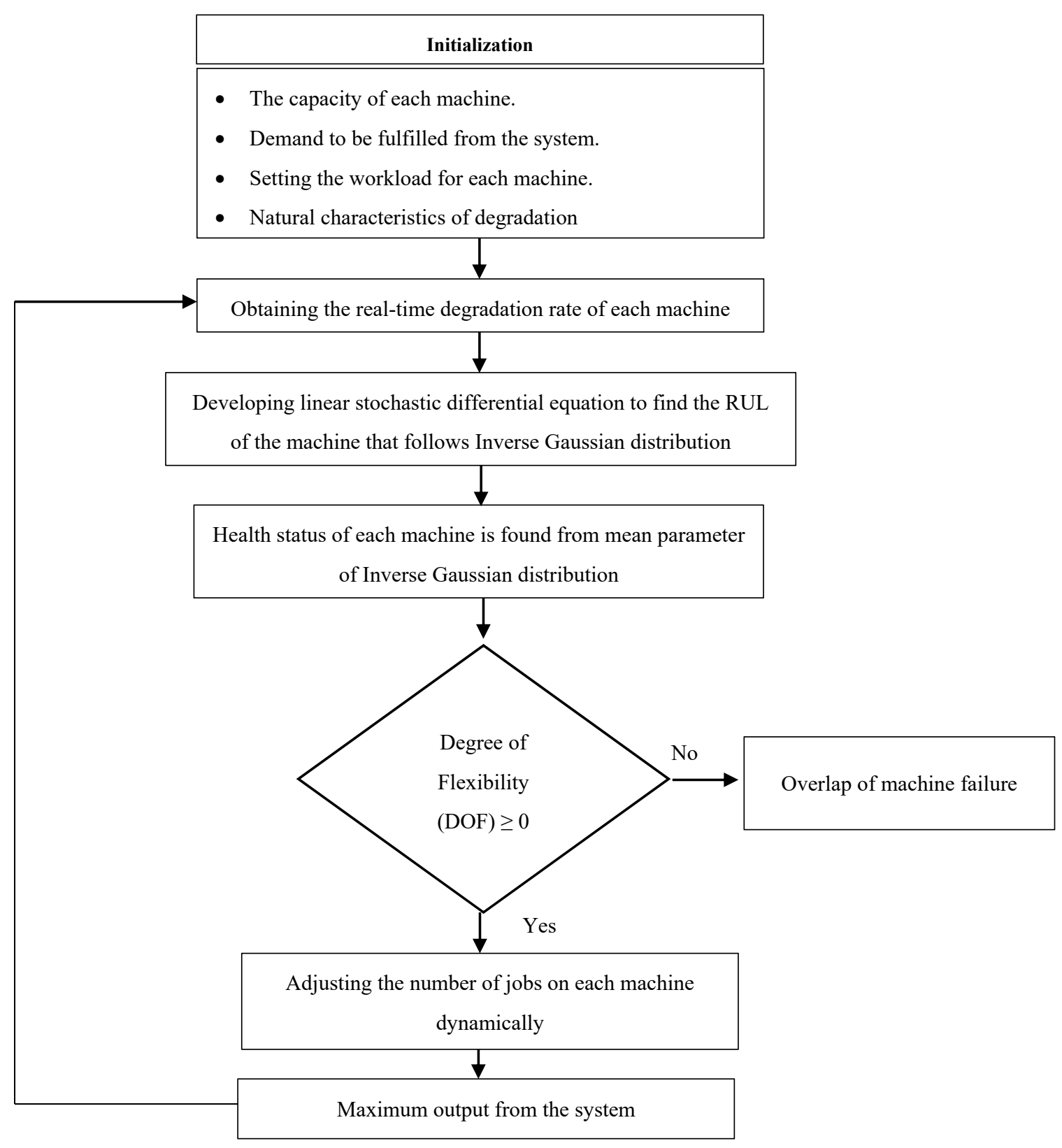

Figure 2. Proposed degradation framework.

The framework depicts a tool for decision-making by delivering the condition of the machine at each decision epoch and predicting the real-time health status of machines in a manufacturing flexible systems scenario. Recall, the machines are identical in nature, where the assignment of the jobs on each machine is carried out based on the capacity and the demand of the system. Though the machines are identical in nature, their degradation rate differs not only concerning the number of jobs and demand but also due to the natural characteristics such as processing variations, friction, material inhomogeneity, etc. These characteristics provide information about the real-time degradation rate of each machine, 
denoted as $i_{(q, r)}(x)$. With the available degradation information of each machine, a linear stochastic differential equation is developed as follows:

$$
d A_{(q, r)}(x)=i_{(q, r)}(x) d t+d W_{(q, r)}(x)
$$

Here, $A_{(q, r)}(x)$ represents the amplitude of degradation signals for the machine $q, r$ at the time $x$, and $W_{(q, r)}(x)$ is a Brownian motion error function. The formulation of Equation (1) is inspired by the modelling of degradation efforts in the absence of prior degradation information [40]. The main idea here is to develop a job assignment strategy to effectively control acceleration in the degradation rate of machines by considering the relationship shown in Equation (1). Based on the past research efforts made on characterizing the relationship between degradation rate and number of jobs assigned through several mathematical assumptions and historical data, we considered a special case, stating the real-time degradation rate is directly proportional to jobs assigned as shown in Equation (2) below.

$$
i_{(q, r)}(x)=\alpha_{(q, r)} O_{(q, r)}(x)
$$

where $\alpha_{(q, r)}$ is considered as the degradation coefficient of the machine $q, r$. From Equation (2), Equation (1) can be rewritten as below in Equation (3).

$$
d A_{(q, r)}(x)=\alpha_{(q, r)} O_{(q, r)}(x) d t+d W_{(q, r)}(x)
$$

Furthermore, condition monitoring of systems is executed at discrete observation epochs [40]; therefore, we performed the sampling of job adjustment in discrete epochs, i.e., $x_{1}-x_{0}=x_{2}-x_{1}=\ldots=x_{u}-x_{u-1}=\delta x$, where the sampling interval is kept constant, and $x_{u}$ denotes the latest observation epoch. Then, $A_{(q, r)}\left(x_{u}\right)$ is the amplitude of the degradation signal of the machine $q, r$ at time $x_{u}$, and the corresponding jobs assigned are $O_{(q, r)}\left(x_{u-1}\right)$. To facilitate solving, the formulation in Equation (3) can be simplified as below in Equation (4).

$$
\delta A_{(q, r)}\left(x_{u}\right)=\alpha_{(q, r)} O_{(q, r)}\left(x_{u-1}\right) \delta t+W_{(q, r)}\left(x_{u}\right)-W_{(q, r)}\left(x_{u-1}\right)
$$

From the properties of Brownian motion $W_{(q, r)}\left(x_{u}\right)-W_{(q, r)}\left(x_{u-1}\right) \sim N\left(0, d_{(q, r)}^{2} \delta x\right)$. Next, we have the corresponding jobs assigned as $O_{(q, r)}\left(x_{u-1}\right)$ and degradation coefficient $\alpha_{(q, r)}$, the conditional distribution developed by Manupati et al. [38] is expressed as below in Equation (5).

$$
A_{(q, r)}\left(x_{u}\right) \mid O_{(q, r)}\left(x_{u-1}\right), \alpha_{(q, r)} \sim N\left(\alpha_{(q, r)} O_{(q, r)}\left(x_{u-1}\right) \delta x, d_{(q, r)}^{2} \delta x\right)
$$

As per the characteristics of the Wiener process, Brownian motion has an independent increment, stating $\delta A_{(q, r)}\left(x_{1}\right), \ldots, \delta A_{(q, r)}\left(x_{u}\right)$ are statistically independent [32]. As a result, the probability density function of the amplitude function can be evaluated as below in Equation (6).

$$
p\left(\delta A_{(q, r)}\left(x_{u}\right) \mid O_{(q, r)}\left(x_{u-1}\right), \alpha_{(q, r)}\right)=\prod_{i=1}^{u} p\left(\delta A_{(q, r)}\left(x_{i}\right) \mid O_{(q, r)}\left(x_{i-1}\right), \alpha_{(q, r)}\right)
$$

where $\delta A_{(q, r)}\left(x_{u}\right)=\left[\delta A_{(q, r)}\left(x_{1}\right), \ldots, \delta A_{(q, r)}\left(x_{u}\right)\right]$ and $O_{(q, r)}\left(x_{u-1}\right)=\left[O_{(q, r)}\left(x_{0}\right), \ldots, O_{(q, r)}\right.$ $\left.\left(x_{u-1}\right)\right]$. Here, the random variable $\alpha_{(q, r)}$ is modelled, whose prior distribution was normal distribution with mean $\beta_{(q, r)}$ and variance $\gamma_{(q, r)}^{2}$. This prior distribution is updated to get posterior distribution with the help of a Bayesian approach by the use of measurements 
that are collected in real time [16]. Then, the posterior distribution's mean and variance of degradation coefficient $\alpha_{(q, r)}$ are represented in Equations (7) and (8).

$$
\begin{gathered}
\beta_{(q, r)}\left(x_{u}\right)=\frac{\gamma_{(q, r)}^{2} \sum_{i=1}^{u} \delta A_{(q, r)}\left(x_{i}\right) O_{(q, r)}\left(x_{i-1}\right)+\beta_{(q, r)} d_{(q, r)}^{2}}{\gamma_{(q, r)}^{2} \sum_{i=1}^{u}\left[O_{(q, r)}\left(x_{i-1}\right)\right]^{2} \delta x+d_{(q, r)}^{2}} \\
\gamma_{(q, r)}^{2}\left(x_{u}\right)=\frac{d_{(q, r)}^{2} \gamma_{(q, r)}^{2}}{\gamma_{(q, r)}^{2} \sum_{i=1}^{u}\left[O_{(q, r)}\left(x_{i-1}\right)\right]^{2} \delta x+d_{(q, r)}^{2}}
\end{gathered}
$$

Next, the posterior mean of degradation coefficient assists in updating the residual life distribution of each machine that follows inverse Gaussian (IG) distribution developed [14] as shown below in Equation (9).

$$
P\left(T_{(q, r)} \leq x \mid A_{(q, r)}\left(x_{u}\right), O_{(q, r)}\left(x_{u}\right), \alpha_{(q, r)}\right) \sim \mathrm{IG}\left(x ; \mu_{(q, r)}\left(x_{u}\right), S_{(q, r)}\left(x_{u}\right)\right)
$$

where IG $\left(t_{; ., .}\right)$indicates the cumulative distribution function with $\mu_{(q, r)}\left(x_{u}\right)=\left(F_{(q, r)}-\right.$ $\left.A_{(q, r)}\left(x_{u}\right)\right) /\left(\alpha_{(q, r)} O_{(q, r)}\left(x_{u}\right)\right) S_{(q, r)}\left(x_{u}\right)=\left(\left[F_{(q, r)}-A_{(q, r)}\left(x_{u}\right)\right]^{2}\right) /\left(d_{(q, r)}^{2}\right)$ and as the mean parameter and the shape parameter of an IG distribution, respectively. Here, to estimate $\alpha_{(q, r)}$ at a certain decision epoch, we propose to replace $\alpha_{(q, r)}$ with the posterior mean $\beta_{(q, r)}\left(x_{u}\right)$ which in turn helps in finding the approximated mean parameter of the IG distribution, i.e., $\mu_{(q, r)}\left(x_{u}\right)=\left(F_{(q, r)}-A_{(q, r)}\left(x_{u}\right)\right) /\left(\beta_{(q, r)}\left(x_{u}\right) O_{(q, r)}\left(x_{u}\right)\right)$. Here, $\left(F_{(q, r)}-A_{(q, r)}\left(x_{u}\right)\right) / \beta_{(q, r)}\left(x_{u}\right)$ is the health status of the machine $q, r$ at the time $x$ represented by $d i_{(q, r)}\left(x_{u}\right)$. As a result, the predicted residual life (mean parameter of IG distribution) can be shown below in Equation (10).

$$
\mu_{(q, r)}\left(x_{u}\right)=\frac{d i_{(q, r)}\left(x_{u}\right)}{O_{(q, r)}\left(x_{u}\right)}
$$

After finding each machine's health status value, $d i_{(q, r)}\left(x_{u}\right)$, the degree of flexibility of the system is checked according to which the number of jobs is assigned dynamically to prevent the simultaneous multiple-machine failure, which is the primary objective of this study. This procedure repeats for every trial until maximum throughput is achieved.

\section{Development of a Job Adjustment Methodology}

We formulate our methodology for dynamically assigning jobs as a minimization problem that controls the degradation of machines by modifying the remaining task at hand. Given the posterior mean of the degradation coefficient, $\alpha_{(q, r)}$, of functioning machines, $\beta_{(1,1)}\left(x_{u}\right) \ldots \beta_{\widetilde{N}(u)}\left(x_{u}\right)$, and the corresponding degradation levels, $A_{(1,1)}\left(x_{u}\right) \ldots A_{(\widetilde{N}(u))}\left(x_{u}\right)$, the average degradation of all machines at the next decision epoch is minimized by adjusting the jobs $O_{(1,1)}\left(x_{u}\right) \ldots O_{(\widetilde{N}(u))}\left(x_{u}\right)$ as shown in Equation (11) and it is summation of two parts. The first part $\sum_{q=1, r=1}^{\widetilde{N}\left(x_{u}\right)}\left[\beta_{(q, r)}\left(x_{u}\right) O_{(q, r)}\left(x_{u}\right) \delta x\right]$ indicates the incremental growth in the degradation rate of the system concerning time. Meanwhile, the second part $A_{(q, r)}\left(x_{u}\right)$ measures the degradation signal amplitude of the machine $q, r$ at the time $x$.

Objective function: minimize $Z$, where

$$
\mathrm{Z}=\frac{1}{\widetilde{N}\left(x_{u}\right)} \sum_{q=1, r=1}^{\widetilde{N}\left(x_{u}\right)}\left[\beta_{(q, r)}\left(x_{u}\right) O_{(q, r)}\left(x_{u}\right) \delta x+A_{(q, r)}\left(x_{u}\right)\right]
$$


Subject to the following constraints:

$$
\begin{aligned}
& \sum_{q=1, r=1}^{\widetilde{N}\left(x_{u}\right)} O_{(q, r)}\left(x_{u}\right)=\min \left(\sum_{q=1, r=1}^{\widetilde{N}\left(x_{u}\right)} C_{(q, r)}, D\right) \\
& O_{(1,1)} x_{(u)} \geq \ldots \geq O_{\left(\widetilde{N}\left(x_{u}\right)\right)}\left(x_{u}\right) \\
& 0 \leq O_{(q, r)}\left(x_{u}\right) \leq C_{(q, r)}, \quad q, r \in 1, \ldots, N \\
& \frac{E_{(q, r)} \delta x}{4}\left[O_{(q, r)}\left(x_{u}\right)+O_{(q, r+1)}\left(x_{u}\right)\right]^{2} \leq d i_{(q, r+1)} x_{(u)} O_{(q, r)}\left(x_{u}\right)-d i_{(q, r)}\left(x_{u}\right) O_{(q, r+1)}\left(x_{u}\right) \\
& \text { for } q \in 1,2, \ldots, \widetilde{N}\left(x_{u}\right) \\
& r \in 1,2, \ldots, \widetilde{N}\left(x_{u}\right)-1 \\
& \frac{E_{(q, r)} \delta x}{4}\left[O_{(q, r)}\left(x_{u}\right)+O_{(q+1, r+1)}\left(x_{u}\right)\right]^{2} \leq d i_{(q+1, r+1)} x_{(u)} O_{(q, r)}\left(x_{u}\right)-d i_{(q, r)}\left(x_{u}\right) O_{(q+1, r+1)}\left(x_{u}\right) \\
& \text { for } q \in 1,2, \ldots, \widetilde{N}\left(x_{u}\right)-1 \\
& r \in 1,2, \ldots, \widetilde{N}\left(x_{u}\right)-1 \\
& \frac{E_{(q, r)} \delta x}{4}\left[O_{(q, r)}\left(x_{u}\right)+O_{(q+1, r)}\left(x_{u}\right)\right]^{2} \leq d i_{(q+1, r)} x_{(u)} O_{(q, r)}\left(x_{u}\right)-d i_{(q, r)}\left(x_{u}\right) O_{(q+1, r)}\left(x_{u}\right) \\
& \text { for } q \in 1,2, \ldots, \widetilde{N}\left(x_{u}\right)-1 \\
& r \in 1,2, \ldots, \widetilde{N}\left(x_{u}\right) \\
& \frac{E_{(q, r)} \delta x}{4}\left[O_{(q, r)}\left(x_{u}\right)+O_{(q+a, r+1)}\left(x_{u}\right)\right]^{2} \leq d i_{(q+a, r+1)} x_{(u)} O_{(q, r)}\left(x_{u}\right)-d i_{(q, r)}\left(x_{u}\right) O_{(q+a, r+1)}\left(x_{u}\right) \\
& \text { for } r=1 \\
& q \in 1,2, \ldots, \widetilde{N}\left(x_{u}\right) \\
& a \in 1,2, \ldots, \widetilde{N}\left(x_{u}\right)-1 \\
& \frac{E_{(q, r)} \delta x}{4}\left[O_{(q, r)}\left(x_{u}\right)+O_{(q, r+a)}\left(x_{u}\right)\right]^{2} \leq d i_{(q, r+a)} x_{(u)} O_{(q, r)}\left(x_{u}\right)-d i_{(q, r)}\left(x_{u}\right) O_{(q, r+a)}\left(x_{u}\right) \\
& \text { for } r=1 \\
& \mathrm{q} \in 1,2, \ldots, \tilde{N}\left(x_{u}\right) \\
& a \in 1,2, \ldots, \widetilde{N}\left(x_{u}\right)-1 \\
& \frac{E_{(q, r)} \delta x}{4}\left[O_{(q, r)}\left(x_{u}\right)+O_{(q+a, r+b)}\left(x_{u}\right)\right]^{2} \leq d i_{(q+a, r+b)} x_{(u)} O_{(q, r)}\left(x_{u}\right)-d i_{(q, r)}\left(x_{u}\right) O_{(q+a, r+b)}\left(x_{u}\right) \\
& \text { for } q, r=1 \\
& a \in 1,2, \ldots, \widetilde{N}\left(x_{u}\right)-1 \\
& b \in 0,1,2, \ldots, \widetilde{N}\left(x_{u}\right)-1
\end{aligned}
$$

The purpose of the objective function is to ensure that, on average, the failure of all machines occurs at the slowest rate, shown in Equation (11).

Recall, in the system, when the demand of the system is lower than its capacity, the throughput rate is equivalent to demand. Conversely, if the capacity is less than the system's demand, then the system's capacity becomes the throughput rate. This constraint is determined as presented in Equation (12). Despite the fact that flexibility in a system develops a certain amount of robustness for production, it will become ineffectual if the simultaneous breakdown occurs in multiple machines exceeding a certain limit. Therefore, to prevent multiple machine failures at a time, we proposed a method that assigns machines having poorer health status, with a greater workload. The fundamental assumption of this approach is that a greater workload speeds up the process of degradation and, thus, distinguishes these machine's anticipated failure time from that of the others, i.e., assigning $O_{(1,1)}\left(x_{u}\right) \geq O_{(1,2)}\left(x_{u}\right) \geq \ldots \geq O_{(q, r)}\left(x_{u}\right)$ for machines having health status $d i_{(1,1)}\left(x_{u}\right) \leq d i_{(1,2)}\left(x_{u}\right) \leq \ldots \leq d i_{(q, r)}\left(x_{u}\right)$, where $O_{(q, r)}\left(x_{u}\right)$ and $d i_{(q, r)}\left(x_{u}\right)$ denote the number of jobs assigned and health status, respectively, of machine $q, r$ calculated at time $x_{u}$, with $\widetilde{N}\left(x_{u}\right)$ indicating the number of functional machines computed at time $x_{u}$. This method as a constraint is reflected in Equation (13). The constraint in Equation (14) refers to the allotment of a non-negative quantity of jobs to the respective machines. 
To intercept the system from breakdown, the key challenge is to prevent the overlap of machine failure. The solution to this problem is that the failure of a machine should occur after the repair of another machine as stated in Equation (21) as for a one-degree flexible system.

$$
\mu_{(q, r)}\left(x_{u}\right)+E_{(q, r)} \delta x \leq \mu_{(q, r+1)}\left(x_{u}\right)
$$

From Equation (10), Equation (21) can be rewritten as shown in Equation (22)

$$
E_{(q, r)} \delta x O_{(q, r)}\left(x_{u}\right) O_{(q, r+1)}\left(x_{u}\right) \leq d i_{(q, r)}\left(x_{u}\right) O_{(q, r)}\left(x_{u}\right)-d i_{(q, r+1)}\left(x_{u}\right) O_{(q, r+1)}\left(x_{u}\right)
$$

While solving, it results in nonconvex quadratic programming equations that are NP-hard in nature. An algorithm has been proposed by [41-44] that provides an optimal solution to the nonconvex quadratically constrained quadratic programming problems by finding a convex space, covering the original nonconvex space. Later on, Radu et al. [45] addressed certain challenges that arise while optimizing nonconvex problems, and further proposed a cutting plate strategy to recognize strong cuts to select and generate to improve solutions by using a branch and cut algorithm. The drawback of using this mentioned approach for our problem is that an optimal solution may not be feasible for the nonconvex space, providing misleading results. In this paper, we search for a convex subspace in the nonconvex space so that until unless there is an optimal solution, it falls under the feasible region and prevents the overlap of machine failures. Based on Hao et al. [16], we utilized the arithmetic mean-geometric mean inequality to convert the nonconvex form from which the constraint in Equation (15) is generated.

For a one-degree flexible system, the overlap of machine failure is controlled by Equation (15). Recall, as flexibility increases the availability of machines for adjusting jobs increases. As a result, for a two-degree flexible environment, the problem is controlled by Equations (15) and (16). Similarly, Equations (15), (17), and (18) prevent the intersection of machine failure in the semi-flexible system. Meanwhile, in a fully flexible system, the problem is to be controlled using the constraints in Equations (19) and (20).

\section{Case Study}

In this section, a case study is provided to evaluate the performance of the proposed configurations and the effectiveness of the method adopted within a fabric weaving industry. The related data are collected from the zone Surat situated in the northern region of India. This industry consists of power loom machines that operate identically to weave fabrics from the thread. The factors that influence the productivity of power looms are equipment factors, technological factors, and manufacturing flexibility [46].

\subsection{Data Gathering and Parameter Setting}

In this paper, the power loom machine degradation data of 1460 machines were considered to validate and verify the proposed model. These 1460 machines operate under 4 proposed configurations with 3 different instances until there is a catastrophic interruption. The number of machines and the degree of flexibility for a particular configuration with different instances and flexibilities is shown in Table 1. An effective arrangement of machines in the configurations has an impact on increasing the performance [47]. In this study, the machine arrangement is planned for each configuration in a particular instance in such a way that maximum production and highest productivity must be achieved. For example, in instance 1 for a one-degree flexible system, the number of machines is 70, arranged in the sequence 10 rows and 7 columns. To capture the real-world characteristics of the power looms, we considered the following parameter settings stated in Table 2. 
Table 1. Overview of the system.

\begin{tabular}{ccccc}
\hline Sr. No. & $\begin{array}{c}\text { Degree of } \\
\text { Flexibility }\end{array}$ & $\begin{array}{c}\text { No. of } \\
\text { Machines } \\
\text { Instance 1 }\end{array}$ & $\begin{array}{c}\text { No. of } \\
\text { Machines } \\
\text { Instance 2 }\end{array}$ & $\begin{array}{c}\text { No. of } \\
\text { Machines } \\
\text { Instance 3 }\end{array}$ \\
\hline 1 & One Degree & 70 & 90 & 110 \\
\hline 2 & Two Degree & 80 & 120 & 140 \\
\hline 3 & Semi-flexible & 100 & 140 & 160 \\
\hline 4 & Highly Flexible & 100 & 150 & 200 \\
\hline
\end{tabular}

Table 2. Parameters for experimentation.

\begin{tabular}{ll}
\hline \multicolumn{1}{c}{ Parameters } & \multicolumn{1}{c}{ Unit } \\
\hline Production of jobs & $\mathrm{kg} /$ day \\
\hline The capacity of each machine & $48 \mathrm{~kg} /$ day \\
\hline Demand for one-degree flexible system & $3400 \mathrm{~kg} /$ day \\
\hline Demand for two-degree flexible system & $4000 \mathrm{~kg} /$ day \\
\hline Demand for semi-flexible system & $5000 \mathrm{~kg} /$ day \\
\hline Demand for fully flexible system & $5250 \mathrm{~kg} /$ day \\
\hline The prior mean for the degradation coefficient of each machine, $\beta_{(q, r)}$ & $5.97 \times 10^{-8}$ inch $/ \mathrm{kg}$ \\
\hline Brownian motion error for the diffusion parameter, $d_{(q, r)}$ & $2.03 \times 10^{-5}$ inch $/$ day \\
\hline Failure threshold of each machine, $F_{(q, r)}$ & 0.004 \\
\hline
\end{tabular}

\subsection{Experimental Procedure}

We investigated the performance of our approach concerning effectiveness in increasing the residual life of machines by comparing our strategy with two other benchmark strategies mentioned in [7], i.e., (1) jobs are assigned equally to each machine, and (2) assignment of jobs is done randomly among the machines in a given particular configuration. To be more specific, on each observation epoch, for the first benchmark, an equal number of jobs are assigned to each machine in the system, while in benchmark 2 , all possible solutions of the number of jobs assignment are identified, and one is randomly selected from the entire solution set. Next, for the proposed methodology, based on the degradation framework in Section 3, the rate of degradation of each machine in each decision epoch was calculated. Further, based on the health status of the machine, a number of jobs were assigned to it following the methodology in Section 4. The experimentation on each configuration in each instance simultaneously was conducted for 350 days. The observation time for each decision epoch was considered as 1 day.

To examine the performance and enumerate the results, we contemplated two performance indices: (1) the occurrence of a failure in machines for the first time and (2) loss of production. Since the objective of this paper is to find the degradation information for machines, these indices are more informative for our proposed manufacturing configurations as the loss of production will be influenced if multiple-machine breakdown occurs. Here, the maintenance time for a repaired machine is considered as 3 days according to power loom industry data.

\section{Results and Discussion}

In this section, for 3 different instances of 4 flexible configurations, we ran 12 experiments. For every condition, we plotted the graph by considering the two performance indices as shown in Figures 3-6. The following discussions can be made based on the results obtained. 


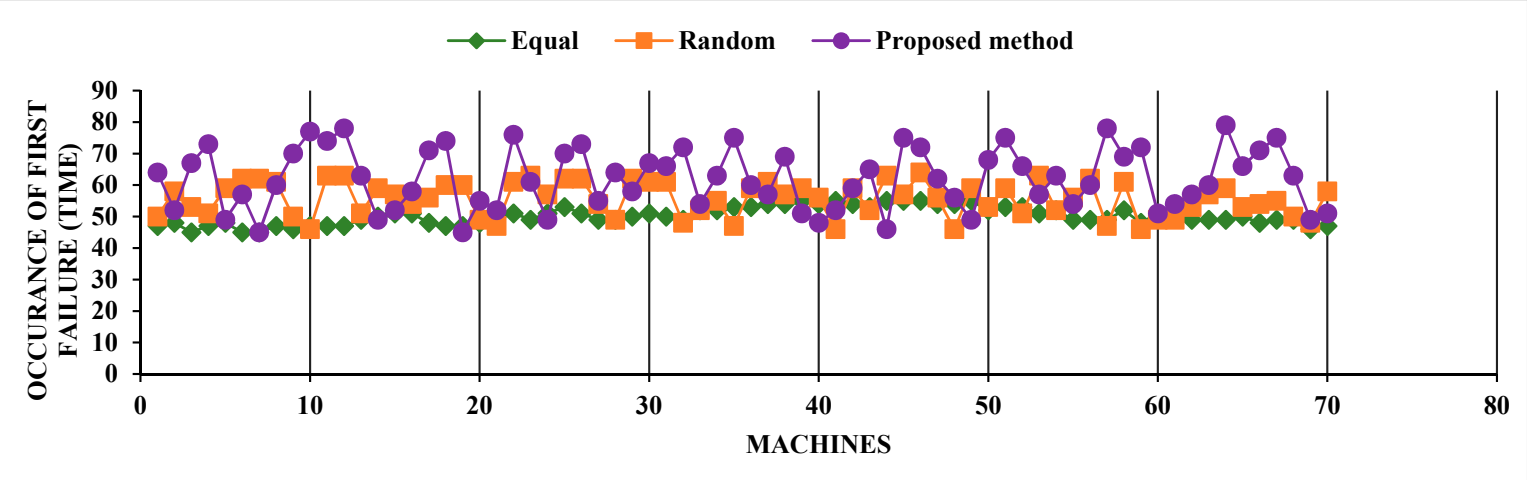

(a) One-degree flexible.

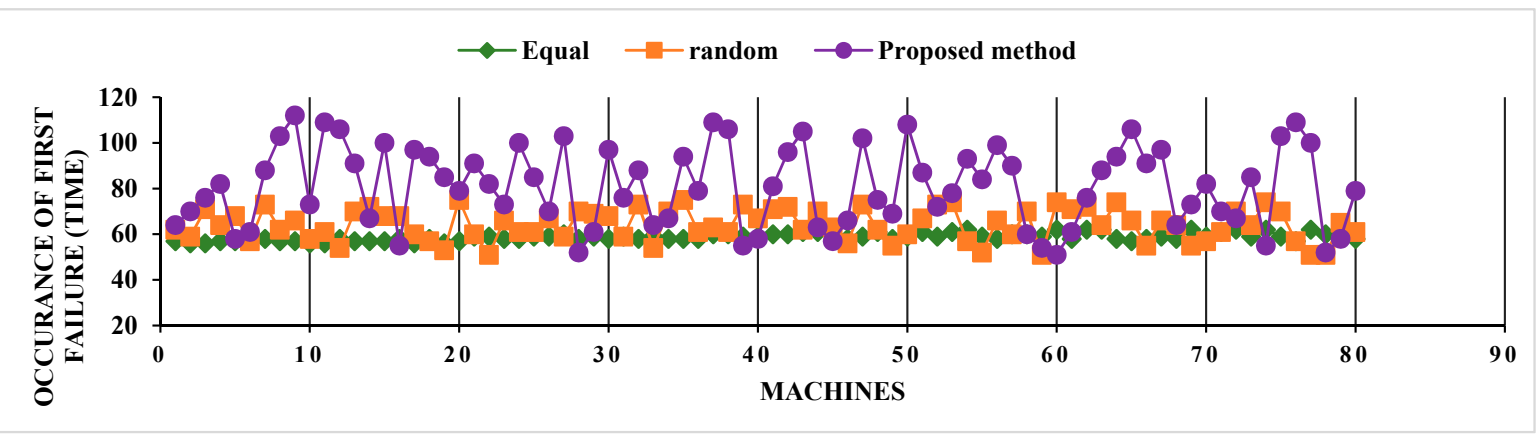

(b) Two-degree flexible.

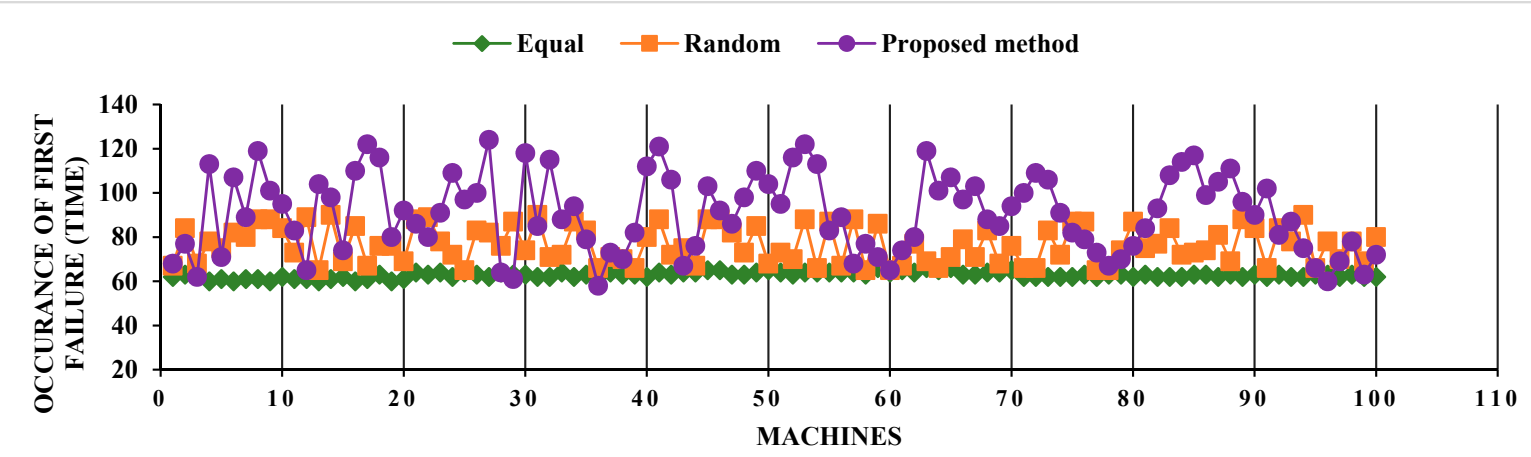

(c) Semi-flexible.

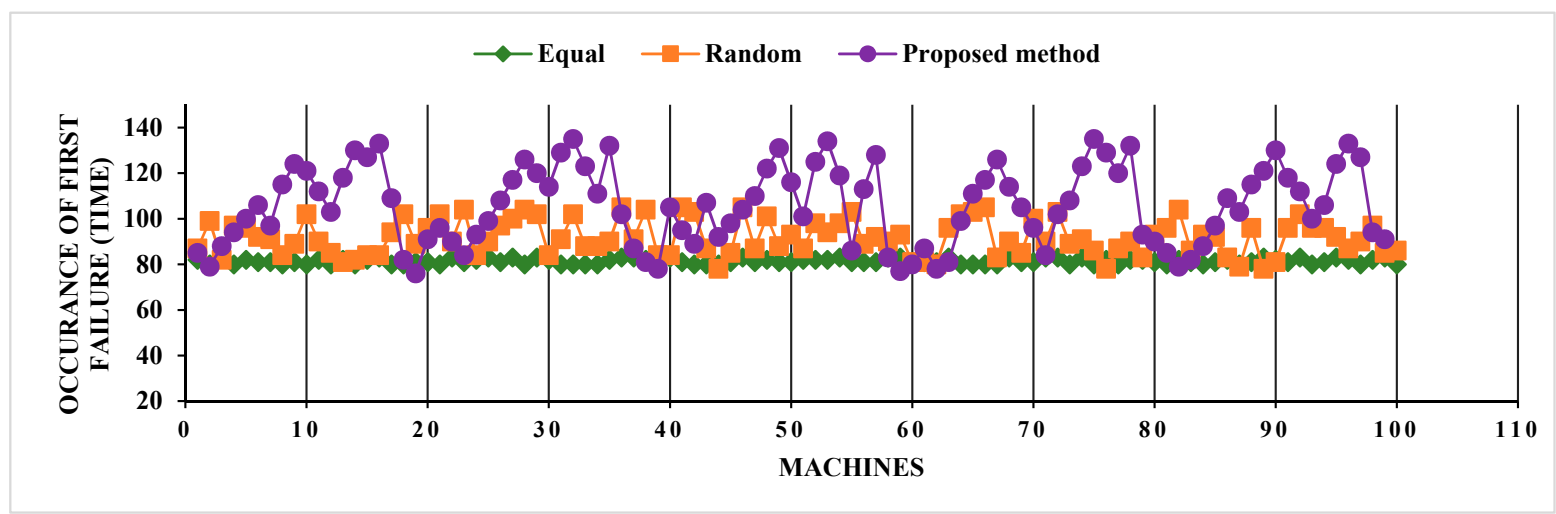

(d) Fully flexible.

Figure 3. Occurrence of machine failure in the system (Instance 1). 


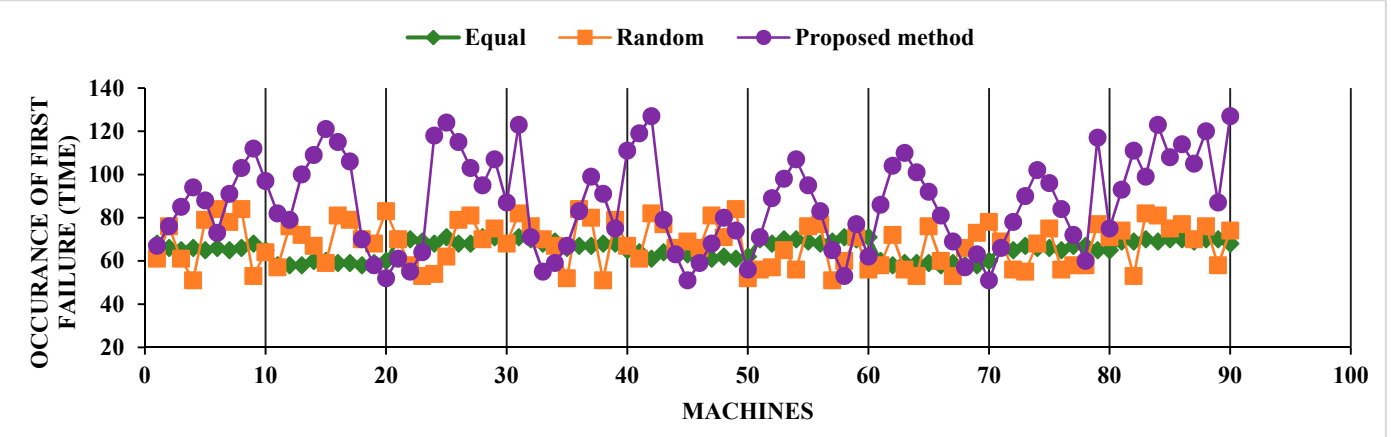

(a) One-degree flexible.

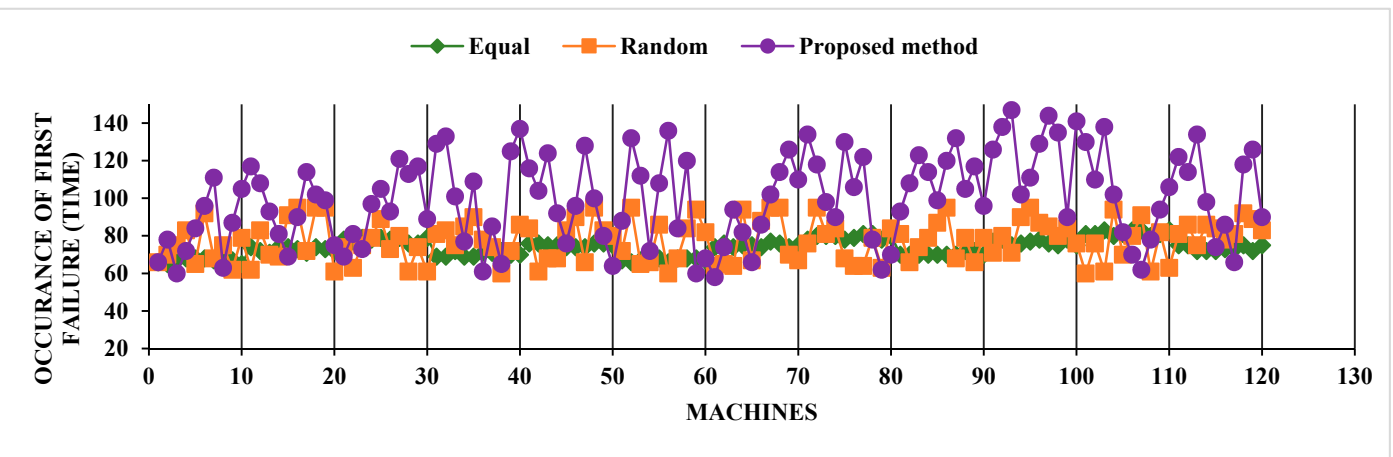

(b) Two-degree flexible.

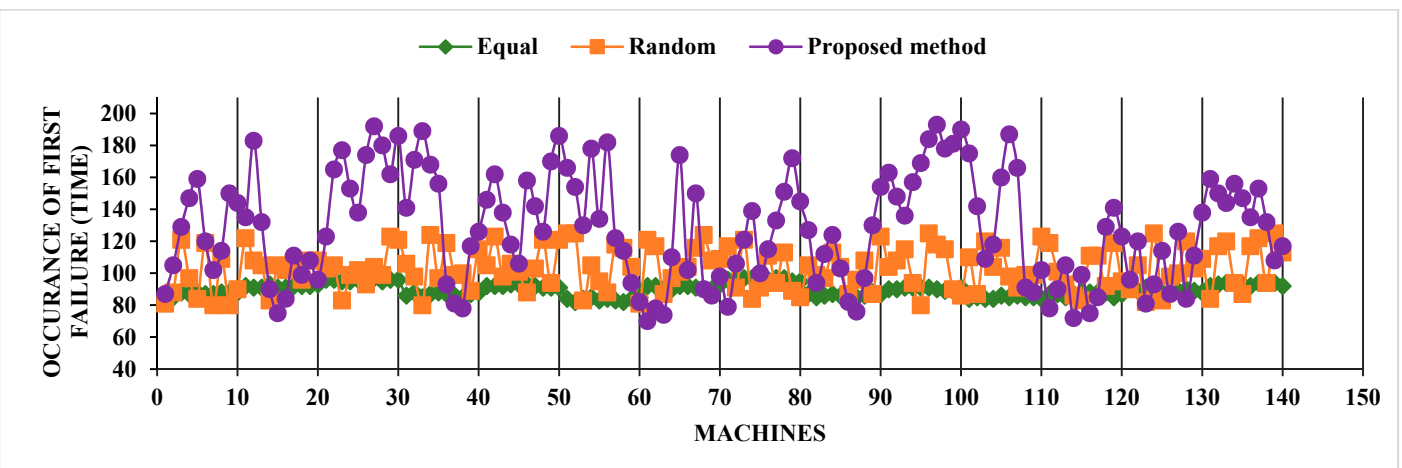

(c) Semi-flexible.

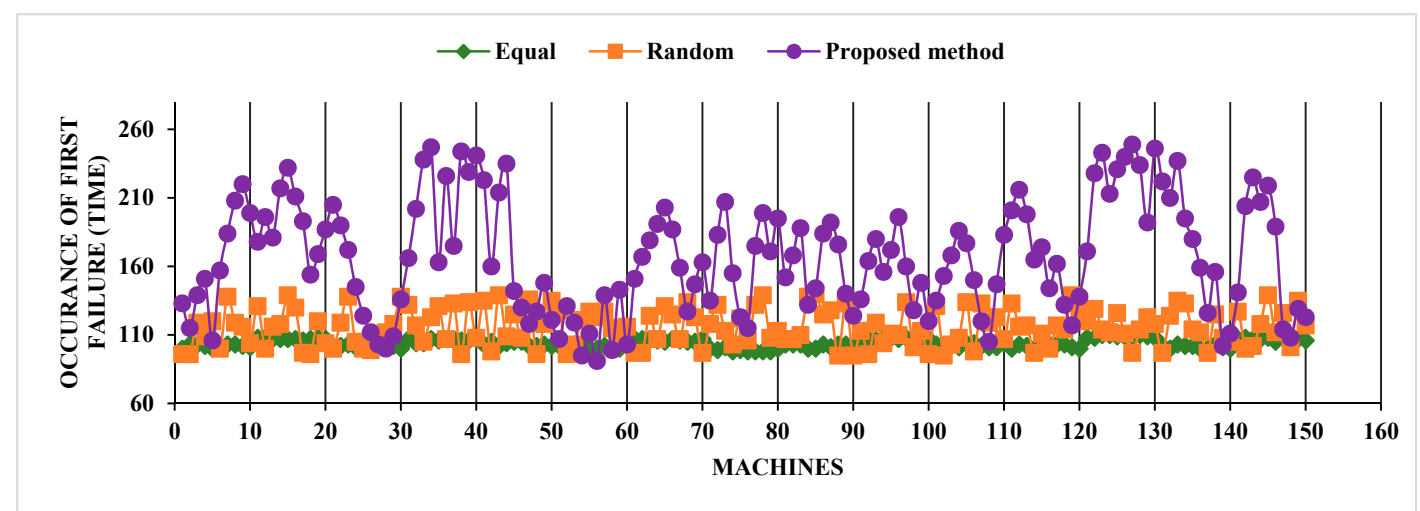

(d) Fully flexible.

Figure 4. The occurrence of machine failure in the system (Instance 2). 


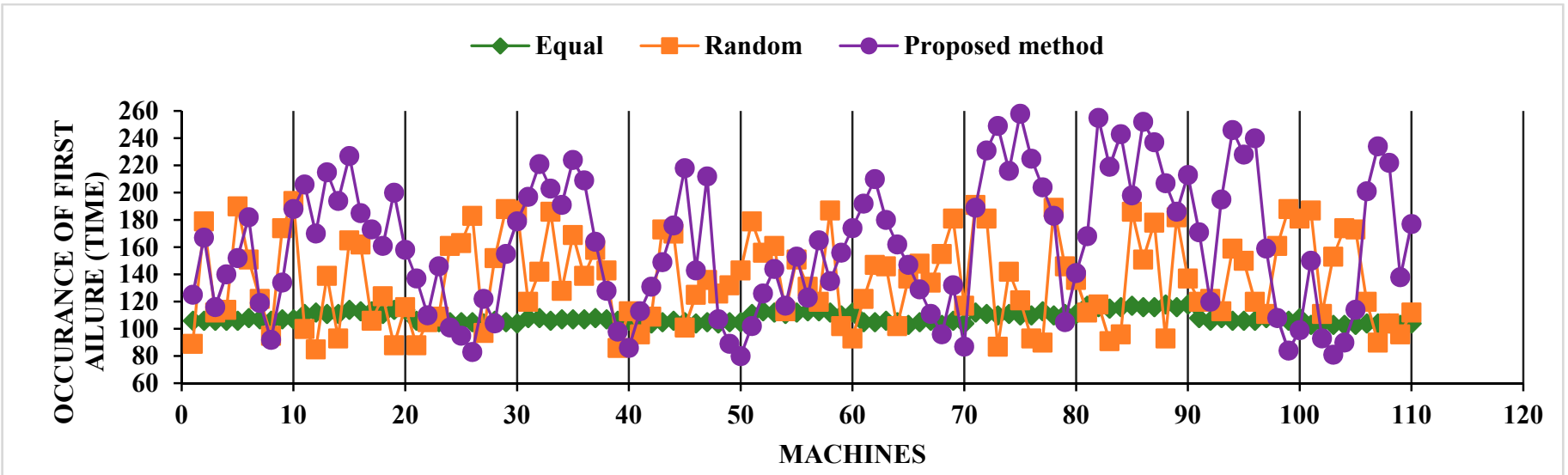

(a) One-degree flexible.

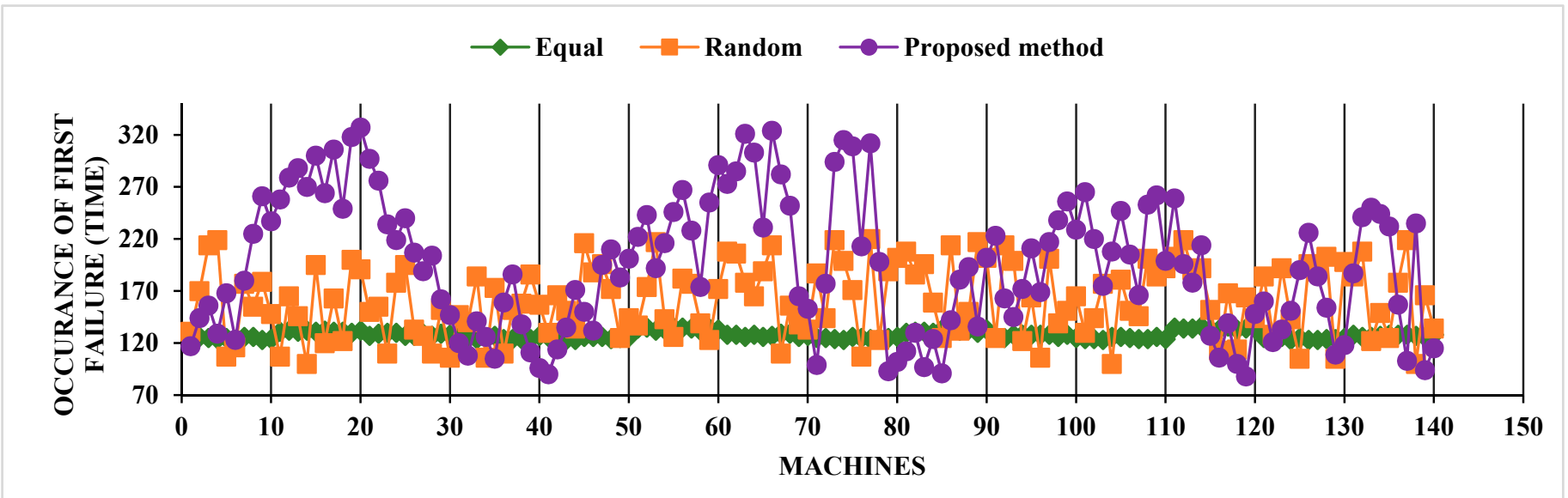

(b) Two-degree flexible.

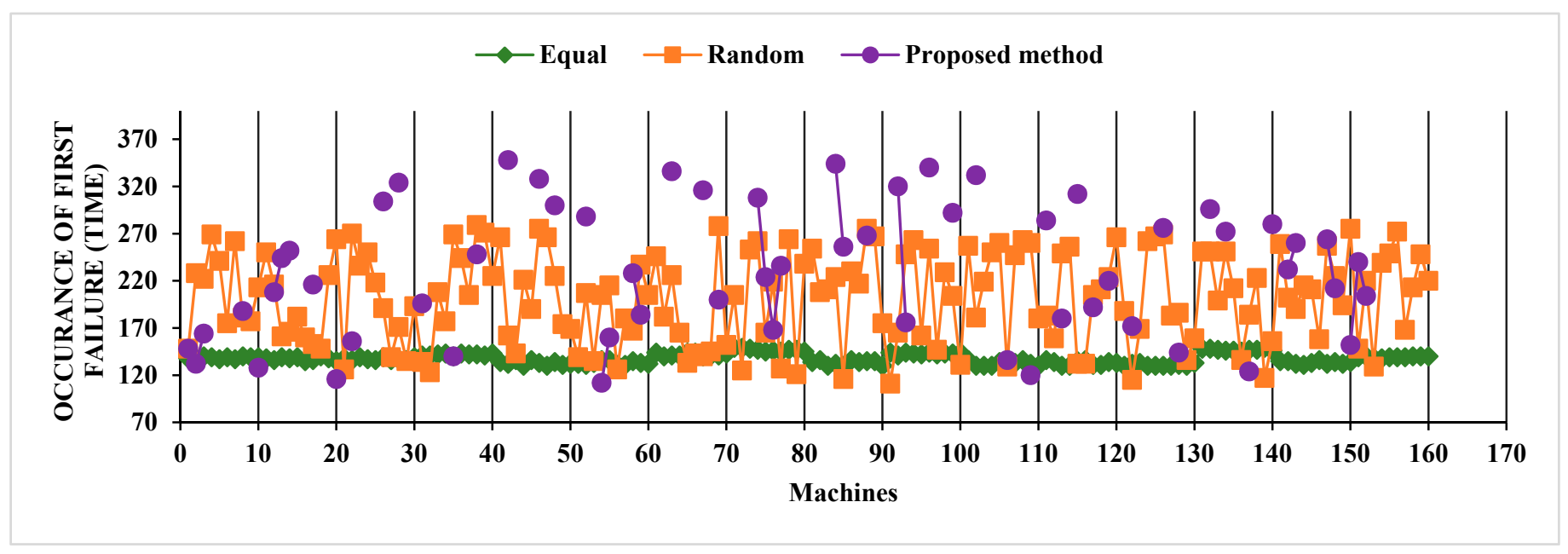

(c) Semi-flexible.

Figure 5. Cont. 


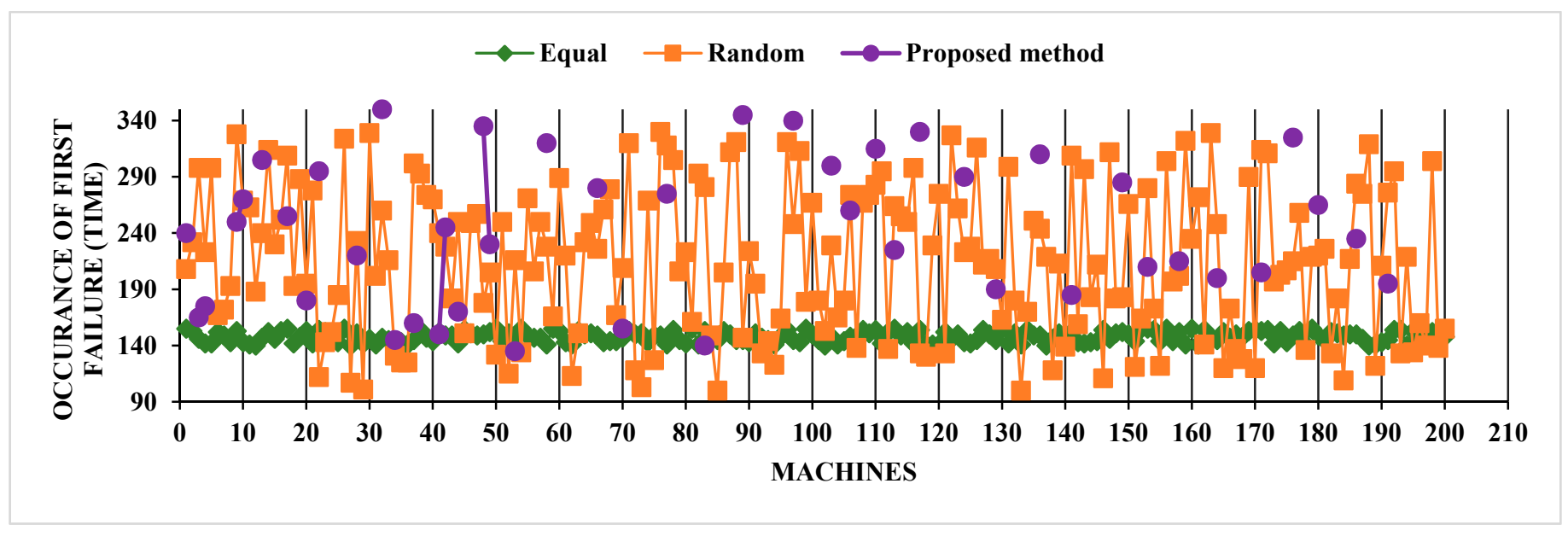

(d) Fully flexible.

Figure 5. Occurrence of machine failure in the system (Instance 3).
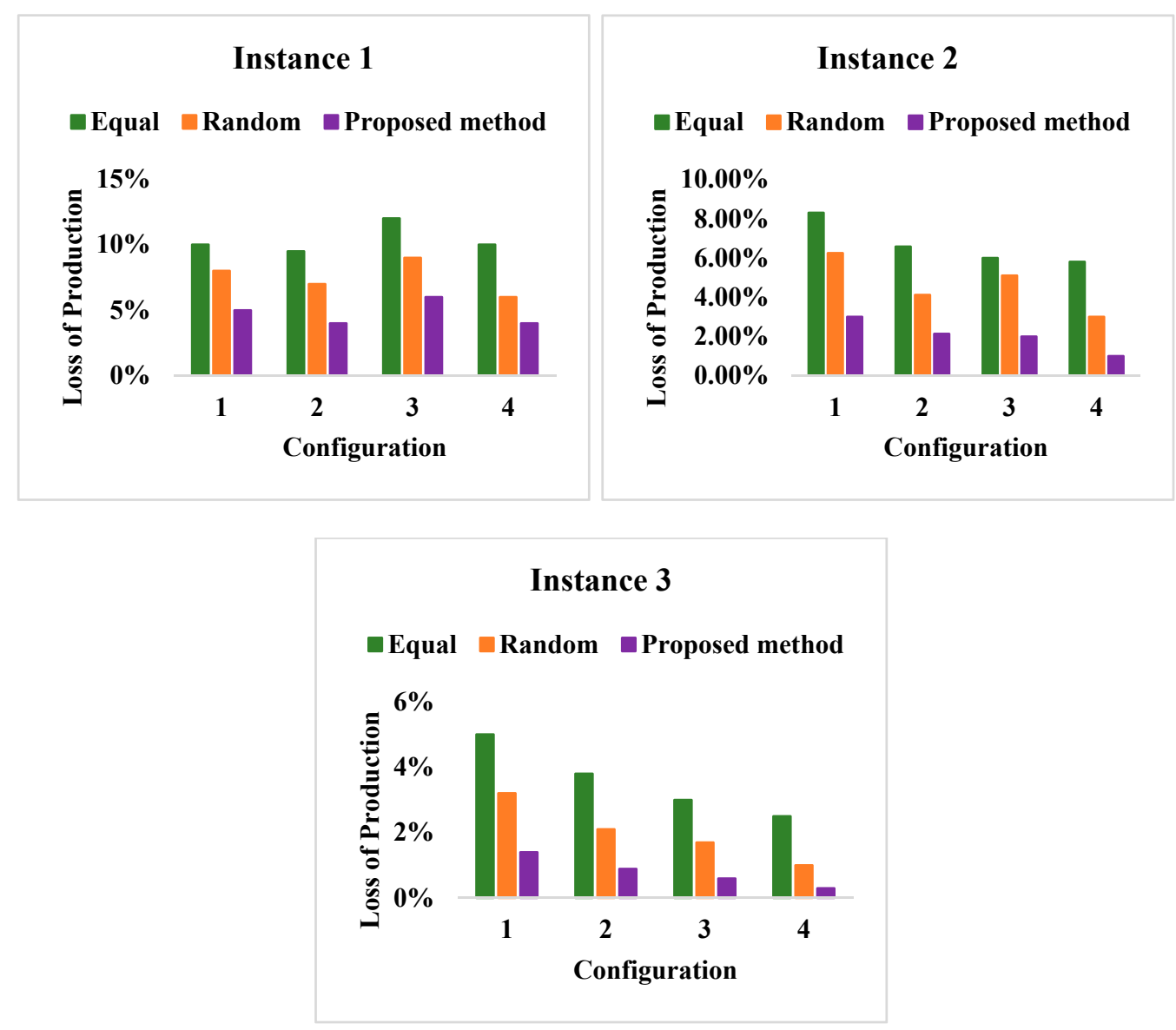

Figure 6. Percentage loss of production.

Figure 3 depicts the experimental results for the first instance of machine configuration. As the demand is high, the machines are made to work up to their limit, accelerating the degradation process, resulting in reduced machine life. Figure 3a shows the result of a one-degree flexible system. From the plot, it should be noticed that when an equal number of jobs are assigned to all the machines in the configuration, the rate of degradation remains similar in all the machines, which leads to failure within a short period, i.e., between the 
41st and the 50th day. However, when the random workload was assigned, a deviation in the range was found between the 40th and the 65th day. In the proposed methodology, it was found that in a row (10 machines) there was a gap of at least 3 days (repair time) in between any two machines' failure. Figure $3 b$ presents the graph of a two-degree flexible system. Here, similar results were observed when the number of jobs was assigned equally and randomly, while in the proposed method a certain level of robustness was found. The result of the semi-flexible system and fully flexible system is articulated in Figure $3 c, d$, respectively. Recall, as flexibility increases, the availability of machines for adjusting the remaining jobs increases. As a result, here in Figure $3 c, d$, when an equal amount of jobs is assigned, the graph depicts almost a straight line stating very close failure times of machines.

The results for instance 2 are illustrated in Figure 4. Here, as the number of machines is more while the demand remains constant, a rise in the average life span of machines was observed. In a one-degree flexible system, as shown in Figure 4a, it was found that machines in a row tend to fail at the same time when an equal number of jobs was assigned to the system. From Figure $4 \mathrm{a}$, it is visible that as one machine in the row fails, the others tend to fail in a similar range of days. For example, machines 1-10 fail approximately between the 65th and the 67th day while machines 11-20 fail approximately in a range 55th-60th day. With the random assignment of jobs, the machines tend to fail randomly, increasing the efficiency of the system somewhat compared to that for an equal workload. In the proposed method, the tendency of multiple-machine breakdown reduced drastically increasing the efficiency of the system. Similar but slightly better results were observed in Figure $4 \mathrm{~b}$ as the degree of flexibility increased compared to that in Figure $4 \mathrm{a}$. For semiflexible and fully flexible systems, results are shown in Figures $4 \mathrm{c}$ and $4 \mathrm{~d}$, respectively; a hike in points in the plot appeared for the proposed method, stating robustness in machineto-machine variability. On the contrary, the performance of the other two assignment techniques reduced as the machine-to-machine variability decreased.

Figure 5 plots the results for instance 3. Compared to the other two instances, a certain level of increased efficiency of the system is observed. Figure $5 a, b$ illustrates the result of a one-degree flexible system and two-degree flexible system, respectively. It can be observed that here, for an equal number of jobs, the results were the same as Figure 4 , but as the number of machines increased, the average time of breakdown was increased. In the case of random assignment of jobs, the deflection in points was in a higher range, reducing the possibility of multiple-machine breakdown, but it was less compared to the proposed methodology. In the case of semi-flexible and fully flexible systems articulated in Figure $5 c, d$, the number of points presenting the machines for the proposed method in the plot was less in comparison to the number of machines considered in instance 3, depicting that not all machines failed during the experimentation. It was found that, in the observed time, only 58 machines failed in the semi-flexible system, while in the fully flexible system the count was 44 .

In Figure 6, 1, 2, 3 and 4 on the horizontal axis indicate one-degree, two-degree, semiflexible, and fully flexible configurations. Based on the experimental results illustrated in Figures 3-6, the performance for equal assignment of jobs is found to be the worst in all the three instances. When the random assignment of jobs was carried out the machines tend to fail randomly, showing slightly better results than the equal assignment of workload reducing the possibility of multiple failures of machines, but still, it failed to control the overall degradation rate, resulting in a system breakdown. In all the three instances, the proposed method showed an effective impact on the efficiency of the system by reducing the degradation process of each machine. When the number of machines was less, the system exhibited a similar degradation process and as a result several machines tended to fail at a similar range of time. 


\section{Conclusions and Future Work}

The stochastic nature of the degradation process always brings challenges to accurately predict the residual life of machines in a system. First, each configuration of machines in a system has a different level of flexibility, which varies the degradation rate of one in comparison to others, thus making it difficult to formulate a degradation model. Second, the workload adjustment in such a system is dependent on the type of configuration, which makes it hard to frame an ideal dynamic workload adjustment strategy. Corresponding to these two major challenges, in this paper, we proposed a degradation model framework that explicates the degradation process and predicts the health status of any machine regardless of the system configuration. The major contribution of this paper is the multiple configuration, dynamic job adjustment strategy that can be applied to any manufacturing system depending upon their flexibility. We applied a Bayesian approach that utilizes the real-time degradation information from the machine to predict the health status of the machine at each decision epoch. Then, based on the degradation condition of the machines, our job assignment methodology assigns the jobs to the machines to prevent the overlap of machine failure in the system. Later, the stochastic degradation model was adapted to numerically evaluate the performance of a real-time manufacturing environment. We compare our proposed method with the other two benchmark strategies, specifically equal job adjustment and random job adjustment. The outcomes depicted that our method consistently shows a certain level of robustness by preventing the overlap of machine failure in each instance and reducing the loss in production to fulfil the required demand. The average percentage of loss in production was $4.75 \%$ in case of the proposed model, which is reduced compared to the average of $10.5 \%$ obtained in the case of equal job adjustment and the average of $7.5 \%$ in random job adjustment in instance 1 . Similarly, the average percentage of loss in production was $2 \%$ in case of proposed model, which is reduced compared to average of $6.67 \%$ in the case of equal job adjustment and average of $4.61 \%$ in random job adjustment in instance 2 . The average percentage of loss in production was $0.75 \%$ in the case of the proposed model, which is reduced compared to the average of $3.75 \%$ in the case of equal job adjustment and the average of $2 \%$ in random job adjustment in instance 3. The minimization of degradation of the system indirectly controlled the failure time of each individual machine; further, the average rate of failure of the machines for the first time was increased. Although these are contemplated as major objectives, there was an impact on efficiency of the system. The proposed model attempted to bring the results closer to real-time situations of sustainable manufacturing system.

This research provides a new direction towards the upgradation modelling of the machines specifically based on predictive maintenance. There are several important areas of research work related to this work. First, this paper considers a linear degradation model for flexible systems, additional efforts can be made by considering the process to be exponential. Second, further studies can be made to predict at what point of time the machine again starts to upgrade after a certain amount of continuous degradation.

Author Contributions: Conceptualization, V.K.M., M.L.R.V., and G.P.; methodology, T.S., V.K.M., B.B.S.N.; software, T.S., and B.B.S.N.; validation, T.S., V.K.M., B.B.S.N., M.L.R.V., and G.P.; formal analysis, T.S., V.K.M.; investigation, T.S., and B.B.S.N.; resources, V.K.M.; data curation, V.K.M.; writing—original draft preparation, T.S., and B.B.S.N.; writing—review and editing, V.K.M., M.L.R.V.; visualization, V.K.M., M.L.R.V.; supervision, V.K.M., M.L.R.V., and G.P.; project administration, V.K.M.; funding acquisition, V.K.M., M.L.R.V., and G.P. All authors have read and agreed to the published version of the manuscript.

Funding: This work has been funded by the Department of Science and Technology, Science and Engineering Research Board (DST-SERB), a statutory body established through an Act of Parliament: SERB Act 2008, Government of India with sanction order no. ECR/2016/001808, and also by the FCT-Fundação para a Ciência e Tecnologia within the R\&D Units Project Scope: UIDB/00319/2020.

Institutional Review Board Statement: Not applicable.

Informed Consent Statement: Not applicable. 
Acknowledgments: The authors thank the Department of Science and Technology, Science and Engineering Research Board (DST-SERB), the Statutory Body, and Government of India, and also the Department of Production and Systems from University of Minho and the FCT-Fundação para a Ciência e Tecnologia, both from Portugal.

Conflicts of Interest: The authors declare no conflict of interest.

\section{Nomenclature}

$\begin{array}{ll}N & \text { Number of machines } \\ D & \text { Demand per unit time } \\ C_{(q, r)} & \text { Capacity of a machine with respect to position } q \text { and stage } r \\ O_{(q, r)}(x) & \text { Jobs assigned on a machine } q, r \text { at the time } x \\ T H(x) & \text { System's throughput at time } x \\ \widetilde{N}(x) & \text { Number of operational machines at the time } x \\ A_{(q, r)}(x) & \text { Amplitude for degradation wave } q, r \text { at the time } x \\ i_{(q, r)}(x) & \text { Instantaneous degradation rate of the machine } q, r \text { at the time } x \\ W_{(q, r)}(x) & \text { Degradation error of Brownian motion for machine } q, r \text { at the time } x \\ \alpha_{(q, r)}(x) & \text { Degradation coefficient for machine } q, r \\ \beta_{(q, r)} & \text { Mean of prior distribution of } \alpha_{(q, r)} \\ \gamma_{(q, r)}^{2} & \text { The variance of prior distribution of } \alpha_{(q, r)} \\ \delta x & \text { Sampling interval } \\ W_{(q, r)}\left(x_{u-1}\right) & \text { Column vector that constitutes the number of jobs of a machine } q, r \text { from } x_{0} \text { to } x_{u-1} \\ \delta A_{(q, r)}\left(x_{u}\right) & \text { Column vector that constitutes increments in degradation of machine } q, r \text { observed } \\ p_{(.)} & \text {from time intervals } x_{0} \text { to } x_{u-1} \\ \beta_{(q, r)}\left(x_{u}\right) & \text { Probability density function for distribution } \\ \gamma_{(q, r)}^{2}\left(x_{u}\right) & \text { Mean of posterior distribution for } \alpha_{(q, r)} \text { updated at } x_{u} \\ F_{(q, r)} & \text { Variance of the posterior distribution of } \alpha_{(q, r)} \text { updated at } x_{u} \\ I_{G}(.) & \text { Pre-defined failure threshold for a machine } q, r \\ \mu_{(q, r)}\left(x_{u}\right) & \text { An inverse Gaussian distribution for the cumulative distribution function } \\ S_{(q, r)}\left(x_{u}\right) & \text { Mean variable of the conditional residual life distribution of machine } q, r \text { computed } \\ d_{(q, r)}\left(x_{u}\right) & \text { at } x_{u} \\ E_{(q, r)} \delta x & \text { Shape parameter of the conditional residual life distribution of machine } q, r \text { computed } \\ & \text { Degradation indicator of the machine } q, r, \text { which is identified with the severity of } \\ \text { degradation } & \text { Repair time of a machine } q, r\end{array}$

\section{References}

1. Wang, S.; Wan, J.; Zhang, D.; Li, D.; Zhang, C. Towards smart factory for industry 4.0: A self-organized multi-agent system with big data based feedback and coordination. Comput. Netw. 2016, 101, 158-168. [CrossRef]

2. Yang, H.-L.; Chang, T.-W.; Choi, Y. Exploring the Research Trend of Smart Factory with Topic Modeling. Sustainability 2018, 10, 2779. [CrossRef]

3. Strozzi, F.; Colicchia, C.; Creazza, A.; Noè, C. Literature review on the 'Smart Factory' concept using bibliometric tools. Int. J. Prod. Res. 2017, 55, 6572-6591. [CrossRef]

4. Kang, Z.; Catal, C.; Tekinerdogan, B. Remaining Useful Life (RUL) Prediction of Equipment in Production Lines Using Artificial Neural Networks. Sensors 2021, 21, 932. [CrossRef]

5. Chryssolouris, G.; Georgoulias, K.; Michalos, G. Production Systems Flexibility: Theory and Practice. IFAC Proc. Vol. 2012, 45, 15-21. [CrossRef]

6. Otoo, M.; Collins, J. Industrial Production and Capacity Utilization: The 2010 Annual Revision; Federal Reserve: Washington, DC, USA, 2011.

7. Chandra, A.; Ahsan, M.; Lahiri, S.; Panigrahi, S.; Manupati, V.; Costa, E. Degradation modeling to predict the residual life distribu-tion of parallel unit systems on benchmark instances. In Proceedings of the World Congress on Engineering, London, UK, 5-7 July 2017; pp. 783-787. Available online: http://www.iaeng.org/publication/WCE2017/WCE2017_pp783-787.pdf (accessed on 16 September 2020).

8. Azadeh, A.; Kolaee, M.H.; Sheikhalishahi, M. An integrated approach for configuration optimization in a CBM system by considering fatigue effects. Int. J. Adv. Manuf. Technol. 2016, 86, 1881-1893. [CrossRef] 
9. Bednar, S.; Rauch, E. Modeling and application of configuration complexity scale: Concept for customized production. Int. J. Adv. Manuf. Technol. 2018, 100, 485-501. [CrossRef]

10. Benderbal, H.H.; Benyoucef, L. Machine layout design problem under product family evolution in reconfigurable manufacturing environment: A two-phase-based AMOSA approach. Int. J. Adv. Manuf. Technol. 2019, 104, 375-389. [CrossRef]

11. Lafou, M.; Mathieu, L.; Pois, S.; Alochet, M. Manufacturing System Configuration: Flexibility Analysis For automotive MixedModel Assembly Lines. IFAC PapersOnLine 2015, 48, 94-99. [CrossRef]

12. Freitas, M.A.; Colosimo, E.A.; Dos Santos, T.R.; Pires, M.C. Reliability assessment using degradation models: Bayesian and classical approaches. Pesqui. Oper. 2010, 30, 194-219. [CrossRef]

13. Kishawy, H.A.; Hegab, H.; Saad, E. Design for Sustainable Manufacturing: Approach, Implementation, and Assessment. Sustainability 2018, 10, 3604. [CrossRef]

14. Venugopal, V.; Saleeshya, P.G. Manufacturing system sustainability through lean and agile initiatives. Int. J. Sustain. Eng. 2018, 12, 159-173. [CrossRef]

15. Gebraeel, N.Z.; Lawley, M.A.; Li, R.; Ryan, J.K. Residual-life distributions from component degradation signals: A Bayesian approach. IIE Trans. 2005, 37, 543-557. [CrossRef]

16. Hao, L.; Liu, K.; Gebraeel, N.; Shi, J. Controlling the Residual Life Distribution of Parallel Unit Systems through Workload Adjustment. IEEE Trans. Autom. Sci. Eng. 2015, 14, 1042-1052. [CrossRef]

17. Song, C.; Liu, K. Statistical degradation modeling and prognostics of multiple sensor signals via data fusion: A composite health index approach. IISE Trans. 2018, 50, 853-867. [CrossRef]

18. Bian, L.; Gebraeel, N.; Kharoufeh, J.P. Degradation modeling for real-time estimation of residual lifetimes in dynamic environments. IIE Trans. 2015, 47, 471-486. [CrossRef]

19. Deutsch, J.; He, D. Using Deep Learning-Based Approach to Predict Remaining Useful Life of Rotating Components. IEEE Trans. Syst. Man, Cybern. Syst. 2018, 48, 11-20. [CrossRef]

20. Ren, L.; Sun, Y.; Cui, J.; Zhang, L. Bearing remaining useful life prediction based on deep autoencoder and deep neural networks. J. Manuf. Syst. 2018, 48, 71-77. [CrossRef]

21. Cipollini, F.; Oneto, L.; Coraddu, A.; Murphy, A.J.; Anguita, D. Condition-based maintenance of naval propulsion systems: Data analysis with minimal feedback. Reliab. Eng. Syst. Saf. 2018, 177, 12-23. [CrossRef]

22. Man, J.; Zhou, Q. Prediction of hard failures with stochastic degradation signals using Wiener process and proportional hazards model. Comput. Ind. Eng. 2018, 125, 480-489. [CrossRef]

23. Amihai, I.; Gitzel, R.; Kotriwala, A.M.; Pareschi, D.; Subbiah, S.; Sosale, G. An Industrial Case Study Using Vibration Data and Machine Learning to Predict Asset Health. In Proceedings of the 2018 IEEE 20th Conference on Business Informatics (CBI), Vienna, Austria, 11-14 July 2018; IEEE: Piscataway, NJ, USA, 2018; Volume 1, pp. 178-185.

24. Matyas, K.; Nemeth, T.; Kovacs, K.; Glawar, R. A procedural approach for realizing prescriptive maintenance planning in manufacturing industries. CIRP Ann. 2017, 66, 461-464. [CrossRef]

25. Ben-Salem, A.; Gharbi, A.; Hajji, A. Environmental issue in an alternative production-maintenance control for unreliable manufacturing system subject to degradation. Int. J. Adv. Manuf. Technol. 2014, 77, 383-398. [CrossRef]

26. Ye, Z.; Cai, Z.; Zhou, F.; Zhao, J.; Zhang, P. Reliability analysis for series manufacturing system with imperfect inspection considering the interaction between quality and degradation. Reliab. Eng. Syst. Saf. 2019, 189, 345-356. [CrossRef]

27. Ni, X.; Zhao, J.; Zhang, X.; Lv, X.; Zhao, J. System degradation process modeling for two-stage degraded mode. In Proceedings of the 2014 Prognostics and System Health Management Conference (PHM-2014 Hunan), Zhangjiajie, China, 24-27 August 2014; Institute of Electrical and Electronics Engineers (IEEE): Piscataway, NJ, USA, 2014; pp. 186-189.

28. Li, N.; Gebraeel, N.; Lei, Y.; Bian, L.; Si, X. Remaining useful life prediction of machinery under time-varying operating conditions based on a two-factor state-space model. Reliab. Eng. Syst. Saf. 2019, 186, 88-100. [CrossRef]

29. Gao, Z.; Hu, Q.-G.; Xu, X.-Y. Residual Lifetime Prediction with Multistage Stochastic Degradation for Equipment. Complexity 2020, 2020, 8847703. [CrossRef]

30. Zhou, R.R.; Serban, N.; Gebraeel, N. Degradation modeling applied to residual lifetime prediction using functional data analy-sis. Ann. Appl. Stat. 2011, 5, 1586-1610. Available online: https://www.jstor.org/stable/23024864 (accessed on 1 October 2020). [CrossRef]

31. Bian, L.; Gebraeel, N. Computing and updating the first-passage time distribution for randomly evolving degradation signals. IIE Trans. 2012, 44, 974-987. [CrossRef]

32. Liu, K.; Gebraeel, N.Z.; Shi, J. A Data-Level Fusion Model for Developing Composite Health Indices for Degradation Modeling and Prognostic Analysis. IEEE Trans. Autom. Sci. Eng. 2013, 10, 652-664. [CrossRef]

33. Ayad, S.; Terrissa, L.S.; Zerhouni, N. An IoT approach for a smart maintenance. In Proceedings of the 2018 International Conference on Advanced Systems and Electric Technologies (IC_ASET), Hammamet, Tunisia, 22-25 March 2018; Institute of Electrical and Electronics Engineers (IEEE): Piscataway, NJ, USA, 2018; pp. 210-214.

34. Nemeth, T.; Ansari, F.; Sihn, W.; Haslhofer, B.; Schindler, A. PriMa-X: A reference model for realizing prescriptive maintenance and assessing its maturity enhanced by machine learning. Procedia CIRP 2018, 72, 1039-1044. [CrossRef]

35. Jin, W.; Liu, Z.; Shi, Z.; Jin, C.; Lee, J. CPS-enabled worry-free industrial applications. In Proceedings of the 2017 Prognostics and System Health Management Conference (PHM-Harbin), Harbin, China, 9-12 July 2017; IEEE: Piscataway, NJ, USA, 2017; pp. 1-7.

36. Lee, J.; Jin, C.; Bagheri, B. Cyber physical systems for predictive production systems. Prod. Eng. 2017, 11, 155-165. [CrossRef] 
37. Terrissa, L.S.; Meraghni, S.; Bouzidi, Z.; Zerhouni, N. A new approach of PHM as a service in cloud computing. In Proceedings of the 2016 4th IEEE International Colloquium on Information Science and Technology (CiSt), Tangier, Morocco, 24-26 October 2016; Institute of Electrical and Electronics Engineers (IEEE): Piscataway, NJ, USA, 2016; pp. 610-614.

38. Manupati, V.K.; Panigrahi, S.; Ahsan, M.; Lahiri, S.; Chandra, A.; Thakkar, J.J.; Putnik, G.; Varela, M.L.R. Estimation of manufacturing systems degradation rate for residual life prediction through dynamic workload adjustment. Sadhana 2019, 44, 30. [CrossRef]

39. Koren, Y.; Hu, S.J.; Weber, T.W. Impact of Manufacturing System Configuration on Performance. CIRP Ann. 1998, 47, 369-372. [CrossRef]

40. Gebraeel, N.; Elwany, A.A.; Pan, J. Residual Life Predictions in the Absence of Prior Degradation Knowledge. IEEE Trans. Reliab. 2009, 58, 106-117. [CrossRef]

41. Al-Khayyal, F.A.; Larsen, C.; Van Voorhis, T. A relaxation method for nonconvex quadratically constrained quadratic programs. J. Glob. Optim. 1995, 6, 215-230. [CrossRef]

42. Audet, C.; Hansen, P.; Jaumard, B.; Savard, G. A branch and cut algorithm for nonconvex quadratically constrained quadratic programming. Math. Program. 2000, 87, 131-152. [CrossRef]

43. Boukouvala, F.; Misener, R.; Floudas, C.A. Global optimization advances in Mixed-Integer Nonlinear Programming, MINLP, and Constrained Derivative-Free Optimization, CDFO. Eur. J. Oper. Res. 2016, 252, 701-727. [CrossRef]

44. Murty, K.G.; Kabadi, S.N. Some NP-complete problems in quadratic and nonlinear programming. Math. Program. 1987, 39, 117-129. [CrossRef]

45. Baltean-Lugojan, R. Exploiting Structure in Nonconvex Quadratic Optimisation. Ph.D. Thesis, Imperial College London, London, UK, 2019. [CrossRef]

46. Shaikh, S.R.; Dulange, S.R. A study of factors affecting productivity of Power Loom Industries. Int. J. Eng. Res. Technol. IJERT 2013, 2, 3174-3180. [CrossRef]

47. Varela, M.; Manupati, V.K.; Panigrahi, S.; Costa, E.; Putnik, G.D. Using social network analysis for industrial plant layout analysis in the context of industry 4.0. Int. J. Ind. Syst. Eng. 2020, 34, 1-19. [CrossRef] 